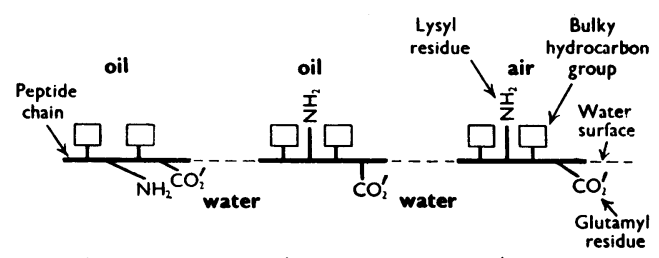

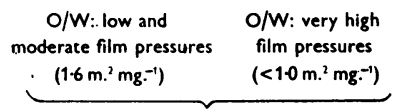

(a)
A/W: moderate

film pressures

(16 $\mathrm{m}^{2} \mathrm{mg}^{-1}$ )

(b)
Fig. 4. Orientations of the $-\left(\mathrm{CH}_{2}\right)_{4} \mathrm{NH}_{2}$ chains in proteins at $(a)$ the oil-water interface, and $(b)$ the air-water interface.

the aqueous phase either in $\mathrm{A} / \mathrm{W}$ monolayers at moderate pressures or in the native protein (where the van der Waals forces of cohesion between the hydrocarbon side chains are also very powerful). When the protein is unfolded at a lipid-water interface the $\epsilon-\mathrm{NH}_{2}$ is much more readily available (Fig. 4), and in this we may find some explanation of the curious and specific biological phenomena mentioned in the introduction.

\section{SUMMARY}

1. The potentials of monolayers of various proteins and amino acid polymers, including a new synthetic amphoteric amino acid polymer, have been measured at the interfaces air-water and oil-water, at $\mathrm{pH}$ 's $2,6 \cdot 8$ and 13. With this new polymer (poly-1:1:2:-L-lysyl-L-glutamyl-L-leucine) all the phenomena shown by protein films can now be reproduced. Other polymers studied were poly-L-lysine, poly-DL-leucine, poly-1:1- $\gamma$ methyl-L-glutamyl-DL-phenylalanine and poly-1:1DL-lysyl-L-glutamic acid.
2. At $\mathrm{pH} 13$ the un-ionized $\epsilon-\mathrm{NH}_{2}$ groups of the lysine residues tend to enter the non-aqueous phase, especially at the air-water interface when the neighbouring amino acid residues in the peptide chain are favourable.

3. The 'unavailability' of such $\epsilon-\mathrm{NH}_{2}$ groups at this interface and in the native protein may be of major biological importance.

The author is deeply indebted to Prof. Sir Eric Rideal, F.R.S., for his continued encouragement throughout the course of this work.

\section{REFERENCES}

Alexander, A. E. \& Teorell, T. (1939). Trans. Faraday Soc. 35, 727.

Cohn, E. J. \& Edsall, J. T. (1943). Proteins, Amino-acids and Peptides, pp. 358-60. New York: Reinhold.

Davies, J. T. (1951 a). Nature, Lond., 167, 193; Z. Elektrochem. 55, 559.

Davies, J. T. (1951 b). Proc. Roy. Soc. A, 208, 224.

Davies, J. T. (1953). Trans. Faraday Soc. 49, 949.

Fraenkel-Conrat, J. \& Fraenkel-Conrat, H. (1950). Biochim. biophys. Acta, 5, 89.

Gerovich, M. \& Frumkin, A. (1936). J. chem. Phys. 4, 624 .

Haurowitz, F. (1950). Chemistry and Biology of Proteins. New York: Academic Press.

Haurowitz, F. \& Schwerin, P. (1940). Enzymologia, 9, 193.

Holtfreter, J. (1946). J. exp. Zool. 101, 355.

Needham, L. (1951). Aspects of Form, ed. by L. L. Whyte. London: Humphries.

Olcott, H. S. \& Fraenkel-Conrat, H. (1947). Chem. Rev. 41, 151.

Porter, R. R. (1948). Biochim. biophys. Acta, 2, 105.

Reid, E. (1951). Nature, Lond., 168, 955.

Sanger, F. (1952). Advanc. Protein Chem. 7, 1.

Ställberg, S. \& Teorell, T. (1939). Trans. Faraday Soc. 35, 1413.

Tristram, G. R. (1949). Advanc. Protein Chem. 5, 83 (Table 37).

\title{
A Colorimetric Method for the Determination of the Principal Metabolites of Nicotinic Acid in Human Urine
}

\author{
BY W. I. M. HOLMAN \\ Medical Research Council Department of Experimental Medicine, University of Cambridge
}

(Received 17 July 1953)

Recent work has shown that $N$-methyl-2-pyridone5 -carbonamide and $N$-methylnicotinamide are the main metabolites of nicotinic acid normally excreted in human urine (Holman \& Lange, 1949; 1950), that no more than a trace of nicotinamide is excreted (Reddi \& Kodicek, 1953), and that nicotinic acid, $N$-methylnicotinuric acid betaine and pyridine nucleotides, and probably nicotinuric acid,

Biochem. 1954, 56 are not normally present (Reddi \& Kodicek, 1953). It therefore seems likely that the sum of the urinary excretions of $N$-methyl-2-pyridone-5-carbonumide and $N$-methylnicotinamide, expressed as nicotinic acid, may prove to be a reliable index of nicotinic acid status in man. Existing methods for the determination of these metabolites, however, are laborious and time consuming and, since the 
methods involve quite different techniques, it is difficult for one analyst to determine both sub. stances at the same time.

It has also been shown (Holman \& Lous, 1951) that $N$-methyl-2-pyridone-5-carbonamide tends to distribute itself in the total body water of man. It is possible that, if a simple method were available for its estimation, this pyridone might provide the basis for a method of estimating body water.

The present investigation was made in an attempt to devise a rapid colorimetric method for the simultaneous determination of $N$-methyl-2-pyridone-5carbonamide and $N$-methylnicotinamide, based on the conversion of the carbonamide group into an amino group by treatment with hypobromite, and diazotization and coupling of the amino compound formed to yield an azo colour. The hypobromite reaction (Hofmann reaction) has long been used in preparative chemistry, but was not thought to have been adapted for analytical purposes. Although there was a possibility that urine might contain substances capable of giving azo colours by the diazotization process alone, it seemed unlikely that any urinary constituent other than derivatives of nicotinic acid would require both hypobromite treatment and diazotization for the development of an azo colour, since this series of reactions is specific for aromatic and heterocyclic amides.

After the present work had been completed, it was discovered that Goodyear \& Murphy (1944) had proposed a method based on the Hofmann reaction for the estimation of nicotinamide in pharmaceutical preparations. They did not, however, apply their method to other metabolites of nicotinic acid nor to the analysis of biological materials. The relatively large amount (75-325 $\mu$ g.) of nicotinamide required for a determination was an important factor limiting the application of the method.

\section{EXPERIMENTAL}

Preliminary experiments showed that a purple azo colour could be formed from $N$-methyl-2-pyridone-5-carbonamide by heating with hypobromite solution, and then acidifying the solution and diazotizing and coupling according to the technique of Bratton \& Marshall (1939), as modified by Smith, Finkelstein, Aliminosa, Crawford \& Graber (1945). A colour was not always formed, however, particularly when the amount of hypobromite was large in relation to that of the pyridone. The amount of bromine utilized during the reaction with the pyridone, as estimated by thiosulphate titration, increased with the excess of hypobromite added up to as much as $8 \mathrm{~g}$. moles $\mathrm{Br} /$ mole of pyridone. Since only $0.5 \mathrm{~g}$. mole $\mathrm{Br} / \mathrm{mole}$ is required for the Hofmann reaction (e.g. see Sidgwick, Taylor \& Baker, 1937), these results suggested that side reactions occurred, probably leading to extensive oxidative breakdown of the pyridone molecule.

Side reactions could probably have been largely prevented by avoiding an excess of bromine, but this technique is not likely to be suitable for analytical purposes, particularly in the presence of urine, which contains many substances capable of reacting with hypobromite. An alternative possibility was examined, namely, adding an excess of hypobromite at room temperature to ensure combination with the carbonamide group of the pyridone, and then removing the excess before heating the solution. Of various substances tested as agents for the removal of excess of bromine, phenol was the most satisfactory, enabling intense colours to be obtained even when a large excess of hypobromite had previously been added to the pyridone. Under suitable conditions a colour could be formed in the presence of as much as $5000 \mathrm{~g}$. moles $\mathrm{Br} /$ mole pyridone. By the use of phenol, azo colours could also be produced from nicotinamide, $N$-methylnicotinamide and $N$-methyl-2pyridone-3-carbonamide. In every case the amount of test substance required to give a colour of suitable intensity for colorimetric measurement was 1-50 $\mu$. The chief optical properties of the colours formed are summarized in Table 1.

A trace of brownish yellow colour was produced by the reagents in the absence of metabolites of nicotinic acid. This colour increased in intensity during the first $45 \mathrm{~min}$. after addition of the coupling agent, but altered only slightly thereafter. Its absorption at $590 \mathrm{~m} \mu$. was equivalent to about $0 \cdot 4 \mu \mathrm{g}$. of $N$-methyl-2-pyridone-5-carbonamide, and that at $500 \mathrm{~m} \mu$. to about $3 \mu \mathrm{g}$. of $N$-methylnicotinamide chloride. Coenzyme I (diphosphopyridine nucleotide) did not yield a colour, the trace of orange produced by a preparation of this substance being accounted for by the nicotinamide which was present as an impurity.

Optimum conditions of heating and concentrations of $\mathrm{NaOH}$, bromine and phenol were ascertained. Nicotinamide and $N$-methylnicotinamide required for maximal colour production a slightly more alkaline hypobromite solution than the pyridones. It was also found with each of

Table 1. Properties of azo colours produced

\begin{tabular}{|c|c|c|c|c|c|c|}
\hline \multirow[b]{2}{*}{ Substance } & \multirow{2}{*}{$\begin{array}{l}\text { Colour } \\
\text { produced }\end{array}$} & \multirow{2}{*}{$\begin{array}{c}\text { Time to reach } \\
\text { maximal intensity }\end{array}$} & \multicolumn{4}{|c|}{ Light absorption at various wavelengths* } \\
\hline & & & $500 \mathrm{~m} \mu$. & $570 \mathrm{~m} \mu$. & $580 \mathrm{~m} \mu$. & $590 \mathrm{~m} \mu$. \\
\hline Nicotinamide & Orange & $\begin{array}{l}8 \text { min. (after } 30 \mathrm{~min} . \\
\text { fades } 4 \% / \mathrm{hr} \text {.) }\end{array}$ & 100 & - & $1 \cdot 2$ & 0.5 \\
\hline$N$-methylnicotinamide & Orange & $\begin{array}{l}8 \text { min. (after } 30 \mathrm{~min} . \\
\text { fades } 4 \% / \mathrm{hr} \text {.) }\end{array}$ & 100 & - & $2 \cdot 7$ & $0 \cdot 3$ \\
\hline $\begin{array}{l}N \text {-methyl-2-pyridone-5- } \\
\text { carbonamide }\end{array}$ & Purple & $\begin{array}{l}1 \mathrm{hr} \text {. (stable } 1-6 \mathrm{hr} \text {. then } \\
\text { fades } 0.1 \% / \mathrm{hr} \text {.) }\end{array}$ & 45 & 100 & 98 & $92 \cdot 5$ \\
\hline $\begin{array}{l}N \text {-methyl-2-pyridone-3- } \\
\text { carbonamide }\end{array}$ & Blue & $2.5 \mathrm{hr}$. (stable $2.5-21 \mathrm{hr}$.) & 27 & 98 & 100 & 98 \\
\hline
\end{tabular}


the four substances that colour production could be considerably increased by protecting the solution from light during the reaction. On the basis of these considerations a method was worked out which was suitable for the colorimetric determination of any one of the four substances when present alone in pure solution.

\section{Recommended method for colour development}

The following solutions are required:

Bromine solution. $12.5 \mathrm{~g}$. $\mathrm{NaBr}$ and $12.5 \mathrm{~g}$. bromine $(4 \mathrm{ml}$.) were dissolved in water and diluted to $100 \mathrm{ml}$. The solution was stable in the refrigerator for at least 2.5 months.

Sodium hypobromite solutions. (a) Pyridone reagent. $4 \mathrm{ml} .2 \cdot 5 \mathrm{~N}-\mathrm{NaOH}$ were diluted with water to about $45 \mathrm{ml}$., $2 \mathrm{ml}$. bromine solution added, and the solution was made to $50 \mathrm{ml}$. with water. The solution was stable for not more than $24 \mathrm{hr}$. in the dark. (b) Reagent for $N$-methylnicotinamide and nicotinamide. Instead of $4 \mathrm{ml}$., $6 \mathrm{ml}$. of $2.5 \mathrm{~N}-\mathrm{NaOH}$ were used.

Other reagents. Aqueous phenol $(0.45 \%, w / v$; stable in refrigerator for at least 2 weeks); $2.4 \mathrm{~N}-\mathrm{HCl} ; \mathrm{NaNO}_{2}(0.1 \%$, $w / v$; stable in a stoppered bottle in the dark for 3 days); ammonium sulphamate $(0.5 \%, \mathrm{w} / \mathrm{v}$; stable in a stoppered bottle in the dark for 2 weeks); $N$-(l-naphthyl)-ethylenediamine dihydrochloride $(0.1 \%, w / v)$ (stable in refrigerator for at least 3 months).

Standard solutions. These were solutions of $N$-methyl-2pyridone-5-carbonamide, $N$-methyl-2-pyridone-3-carbonamide, nicotinamide and $N$-methylnicotinamide chloride, containing $50 \mu \mathrm{g} . / \mathrm{ml}$; 隹 $N$-methylnicotinamide solution was preserved by making $0.1 \mathrm{~N}$ with $\mathrm{HCl}$, the remaining solutions by addition of a little $\mathrm{CHCl}_{3}$; all solutions were stored in a refrigerator and were stable for at least a month.

Procedure. A measured volume of an aqueous solution at pH 7-9 containing 0-50 $\mu \mathrm{g}$. of nicotinamide, $N$-methylnicotinamide, $N$-methyl-2-pyridone-5-carbonamide, or $N$.

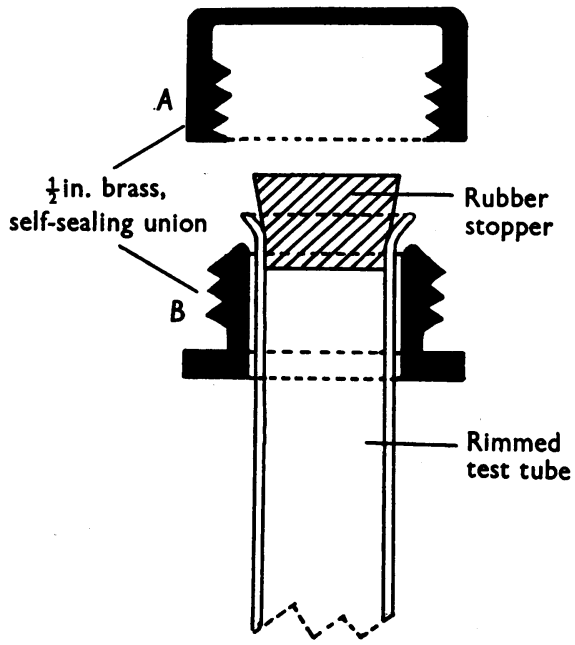

Fig. 1. Method of sealing test tubes during heating process. The bore of part $B$ of the union was sufficiently enlarged to allow the test tube to be passed through as far as the rim. The stopper was inserted in the tube and parts $A$ and $B$ screwed together. methyl-2-pyridone-3-carbonamide, was transferred to a Pyrex, rimmed, $6 \times \frac{5}{8}$ in. test tube and diluted to $4 \mathrm{ml}$. with water. Light being excluded, $1 \mathrm{ml}$. sodium hypobromite solution was added and $4 \mathrm{~min}$. later $1 \mathrm{ml}$. phenol solution. A stopper was inserted and held in place by means of a metal cap (Fig. 1), and the tube heated for $10 \mathrm{~min}$. in a vigorously boiling water bath. After being cooled in running tap-water for 4 min., the cap was removed and $0.5 \mathrm{ml} .2 .4 \mathrm{~N}-\mathrm{HCl}$ was added, followed by $0.5 \mathrm{ml}$. $\mathrm{NaNO}_{2}$ solution. Four min. later $0.5 \mathrm{ml}$. ammonium sulphamate solution was added, and again $4 \mathrm{~min}$. later $0.5 \mathrm{ml}$. of $N$-(1-naphthyl)-ethylenediamine dihydrochloride solution. The stopper was inserted and the contents of the tube were well shaken immediately after each addition. A stop-watch was used to time the intervals between additions. Up to twelve tubes could be carried through this procedure at the same time.

Colour measurement. The colour intensity was measured against a reagent blank prepared at the same time, using a spectrophotometer with $1 \mathrm{~cm}$. cells at a wavelength of $500 \mathrm{~m} \mu$. for nicotinamide and $N$-methylnicotinamide and at $570-590 \mathrm{~m} \mu$. for the pyridones. A Spekker photoelectric absorptiometer with Spectrum Blue-green (480-500 $\mathrm{m} \mu$.), or Spectrum Yellow (570-590 m $\mu$.), filters could also be used. Readings for nicotinamide and $N$-methylnicotinamide were taken at least $10 \mathrm{~min}$. after addition of the coupling agent, readings for $N$-methyl-2-pyridone-5-carbonamide after at least $1 \mathrm{hr}$. and those for $N$-methyl-2-pyridone-3-carbonamide after at least $2.5 \mathrm{hr}$.

Calculation of results. The amount of the test substance present was obtained by reference to a calibration curve prepared at the same time with known amounts of the same substance.

\section{Application of the method to urine}

Analysis of mixtures. Since the colours given by $N$-methylnicotinamide and nicotinamide showed no appreciable absorption at $57.0-590 \mathrm{~m} \mu$. (see Table 1), neither of these substances interfered seriously with the determination of $N$-methyl-2-pyridone-5-carbonamide or $N$-methyl-2-pyridone-3-carbonamide. The error was reduced to a minimum by reading a, $590 \mathrm{~m} \mu$. Mixtures of the two pyridones could be analysed but the individual pyridones could not be differentiated, and neither $N$-methylnicotinamide nor nicotinamide could be determined in the presence of other colourproducing substances. In the analysis of urine, $N$-methyl2-pyridone-5-carbonamide could be determined in the presence of all other metabolites of nicotinic acid, since $N$-methyl-2-pyridone-3-carbonamide is not excreted (Holman \& Lange, 1949). $N$-Methylnicotinamide could be determined only after separation from $N$-methyl-2-pyridone-5-carbonamide and nicotinamide.

Separation of N-methylnicotinamide from N-methyl-2pyridone-5-carbonamide and nicotinamide. Since $N$-methylnicotinamide is a relatively strong base compared with the latter two compounds, attempts were made to effect a separation by differential adsorption on Decalso. Under the conditions of the method of Hochberg, Melnick \& Oser (1945) for the adsorption of $N$-methylnicotinamide from urine, $N$-methyl-2-pyridone-5-carbonamide was not adsorbed to a significant extent, but partial adsorption of nicotinamide occurred. By raising the $\mathrm{pH}$ of adsorption from 4.5 to 7 , however, it was possible to prevent completely the adsorption of nicotinamide and $N$-methyl-2-pyridone5-carbonamide without interfering with the adsorption of 
$N$-methylnicotinamide. After washing of the Decalso, the adsorbed $N$-methylnicotinamide was eluted with $25 \% \mathrm{KCl}$ solution and determined colorimetrically in the absence of the other two metabolites. In a typical experiment the recovery of $N$-methylnicotinamide in the $\mathrm{KCl}$ eluate was $96 \%$ in the presence, and $88 \%$ in the absence, of urine.

Methods for removal of interfering substances from urine. When the colour reaction was carried out in the presence of urine, colour production was to some extent inhibited (see data for untreated urine in Table 2). Interference increased with the volume of urine added and also with the concentration of the particular specimen used. In order to render more comparable the results obtained with urines of differing degrees of concentration, samples of urine were measured in terms of the volume of urine excreted in a given time (see Table 2).

In the separation of $N$-methylnicotinamide by adsorption on Decalso, most of the interfering substances in urine passed through in the filtrate and washings. Samples of the $\mathrm{KCl}$ eluate representing up to $0.8 \mathrm{~min}$. excretion of urine could be analysed directly for $N$-methylnicotinamide without inhibition of colour development. Untreated urine, however, could not be analysed directly.

A partial removal of interfering substances from urine was effected, without altering the concentrations of nicotinic acid metabolites present, by shaking with $\mathrm{Pb}(\mathrm{OH})_{2}$. After this treatment samples of up to $0 \cdot 1 \mathrm{~min}$. excretion could be analysed for pyridone without appreciable inhibition of colour development (see Table 2). A more complete purification was obtained by adsorbing the $N$-methyl-2-pyridone-5-carbonamide in urine on Lloyd's reagent, eluting with $\mathrm{NaOH}$ solution, and then shaking the eluate with $\mathrm{Pb}(\mathrm{OH})_{2}$. Samples representing up to $0.5 \mathrm{~min}$. excretion could then be analysed without interference, but the recovery of the pyridone from the adsorption process was not complete, and was not the same in the presence, as in the absence, of urine (see Table 3). Reducing the strength of the
$\mathrm{NaOH}$ used for elution caused some improvement in the recovery of $N$-methyl-2-pyridone-5-carbonamide but swelling of the Lloyd's reagent occurred when the normality of the $\mathrm{NaOH}$ was $<0.2$, rendering difficult the removal of the eluate. The use of two successive elutions with $\mathrm{NaOH}$ did not appreciably improve the recovery. The method finally adopted involved one elution with $0 \cdot 2 \mathrm{~N}-\mathrm{NaOH}$, errors due to incomplete recovery being avoided by the use of internal standards (see p. 517).

Correction for non-specific colour in urine. When the colour reaction was applied directly to urine, a relatively small amount of a reddish colour was produced, in addition to the brownish yellow due to the reagents, the purple due to $N$-methyl-2-pyridone-5-carbonamide and the orange due to $N$-methylnicotinamide. The amount of this reddish colour was much less in Decalso eluates, or in urines treated with Lloyd's reagent and $\mathrm{Pb}(\mathrm{OH})_{2}$, than in untreated urine. That this colour was not derived from acid amides was shown by the fact that it was produced by the diazotization process alone. Since it absorbed at $500 \mathrm{~m} \mu$., and also to a slight extent at $590 \mathrm{~m} \mu$., its presence would lead to error in the determination of nicotinic acid metabolites in urine unless an appropriate blank determination were made.

Various methods were tested for the production of the red colour in the absence of the colours due to nicotinic acid metabolites. In most cases, the omission of one of the reagents required for the hypobromite reaction, or an alteration in the order of addition of the reagents either led to precipitation of the bromine substitution product of phenol or seriously affected the intensity of the reagent blank. Procedures which were satisfactory in these respects did not completely prevent colour formation by nicotinic acid derivatives. The method finally adopted involved the use of half-strength hypobromite and the addition of the phenol before the hypobromite. Under these conditions only about $0.3 \%$ of the $N$-methyl-2-pyridone-5-carbonamide colour, and $13 \%$ of the $N$-methylnicotinamide colour, developed.

Table 2. Colour development by N-methyl-2-pyridone-5-carbonamide in the presence of normal human urine

\begin{tabular}{|c|c|c|c|}
\hline $\begin{array}{l}\text { Pre-treatment } \\
\text { of urine }\end{array}$ & $\begin{array}{c}\text { Amount of } \\
\text { urine added } \\
\text { (in min. excretion) }\end{array}$ & $\begin{array}{c}\text { Colour } \\
\text { development } \\
(\%)\end{array}$ & $\begin{array}{l}\text { No. of urine } \\
\text { specimens } \\
\text { tested }\end{array}$ \\
\hline- & None & 100 & - \\
\hline $\mathrm{Pb}(\mathrm{OH})_{2}$ & $0 \cdot 0125$ & 102 & 1 \\
\hline $\mathrm{Pb}(\mathrm{OH})_{2}$ & 0.025 & $100-103$ & 3 \\
\hline $\left.\begin{array}{l}\text { No treatment } \\
\mathrm{Pb}(\mathrm{OH})_{2}\end{array}\right\}$ & $0 \cdot 05$ & $\left\{\begin{array}{l}92-100 \\
99-100\end{array}\right.$ & $\begin{array}{l}4 \\
3\end{array}$ \\
\hline $\left.\begin{array}{l}\text { No treatment } \\
\mathrm{Pb}(\mathrm{OH})_{2}\end{array}\right\}$ & $0 \cdot 1$ & $\left\{\begin{array}{l}85-95 \\
97-105\end{array}\right.$ & $\begin{array}{l}4 \\
7\end{array}$ \\
\hline $\mathrm{Pb}(\mathrm{OH})_{2}$ & $0 \cdot 2$ & $94-101$ & 2 \\
\hline
\end{tabular}

Table 3. Recovery of N-methyl-2-pyridone-5-carbonamide from Lloyd's reagent in the presence and absence of urine

Percentage recovered from Lloyd's reagent

\begin{tabular}{|c|c|c|c|}
\hline $\begin{array}{c}2 \\
\text { Elutions with } \\
0.05 \mathrm{~N}-\mathrm{NaOH}\end{array}$ & $\begin{array}{c}2 \\
\text { Elutions with } \\
0 \cdot 1 \mathrm{~N}-\mathrm{NaOH}\end{array}$ & $\begin{array}{c}1 \\
\text { Elution with } \\
0 \cdot 2 \mathrm{~N}-\mathrm{NaOH}\end{array}$ & $\begin{array}{c}1 \\
\text { Elution with } \\
0.5 \mathrm{~N}-\mathrm{NaOH}\end{array}$ \\
\hline $\begin{array}{l}89 \cdot 1 \\
73 \cdot 8\end{array}$ & $\begin{array}{l}89 \cdot 1 \\
71 \cdot 5\end{array}$ & $\begin{array}{l}87 \cdot 0 \\
70 \cdot 2\end{array}$ & $\begin{array}{l}68 \cdot 0 \\
60 \cdot 0\end{array}$ \\
\hline
\end{tabular}

Urine present Urine absent
$73 \cdot 8$ $\mathbf{7 1 \cdot 5}$ 


\section{Methods for determination of N-methyl-2-pyridone- 5-carbonamide in urine}

Rapid method (applicable if rate of excretion exceeds $50 \mathrm{mg} . / 24 \mathrm{hr}$.). The following reagents are required in addition to those already given; $\mathrm{M}-\mathrm{Pb}\left(\mathrm{NO}_{3}\right)_{2}$ solution; $0 \cdot 1 \mathrm{~N}$ borax solution.

Twenty-four hr. specimens of urine were collected under toluene and were stored at room temperature until required for analysis. A suitable sample of urine (1 min. excretion) was measured into each of two centrifuge tubes ( 1 and 2$)$. To tube 2 a known amount of $N$-methyl-2-pyridone-5-carbonamide was added (usually $50 \mu \mathrm{g}$.); to both tubes $2 \mathrm{ml}$. $\mathrm{M}-\mathrm{Pb}\left(\mathrm{NO}_{3}\right)_{2}$ solution was added, followed by sufficient $2.5 \mathrm{~N}-\mathrm{NaOH}$ solution to form $\mathrm{Pb}(\mathrm{OH})_{2}$ and to raise the $\mathrm{pH}$ value of the solution finally to about $9 \cdot 2$. The $\mathrm{pH}$ was tested by external use of indicators or indicator papers, with $0 \cdot 1 \mathrm{~N}$ borax solution as standard. The $\mathrm{NaOH}$ solution (about $1.3 \mathrm{ml}$.) was added slowly with frequent mixing, and the mixture was shaken at intervals for $15 \mathrm{~min}$. thereafter, the pH being checked at intervals. The volume in each case was made to $10 \mathrm{ml}$. with water and the solution mixed, centrifuged and filtered (Whatman no. $40,7 \mathrm{~cm}$., paper); $1 \mathrm{ml}$. of the filtrate from tube 1 was transferred to each of two $6 \times \frac{5}{8}$ in. test tubes (test solution and test solution blank) and $1 \mathrm{ml}$. filtrate from tube 2 to each of a further two test tubes (recovery and recovery blank). To each test tube were added $3 \mathrm{ml}$. water. The colour reaction was applied to the test and recovery solutions in the manner described previously, using hypobromite (a). In the case of the two blank solutions, the hypobromite was diluted $1: 1$ with water before use and the phenol added $4 \mathrm{~min}$. before the hypobromite. The extinction $(E)$ of each solution was measured in a spectrophotometer against distilled water at $590 \mathrm{~m} \mu$., $1 \mathrm{hr}$. after addition of the coupling agent.

Calculation of results. Excretion of $N$-methyl-2-pyridone5-carbonamide (mg./24 hr.)

$$
=\frac{\left(T-B_{t}\right)}{\left(R-B_{r}\right)-\left(T-B_{t}\right)} \times 1.44 \times \frac{A}{M},
$$

where $T$ and $R$ are extinctions ( $E$ values) of test and recovery, $B_{t}$ and $B_{r}$ are extinctions ( $E$ values) of test and recovery blanks, $A=$ amount ( $\mu \mathrm{g}$.) of test substance added for recovery, and $M=$ number of minutes excretion to which the sample of urine taken is equivalent. To express the result in terms of nicotinic acid, it was multiplied by the factor $0 \cdot 809$.

General method for N-methyl-2-pyridone-5-carbonamide in urine. The following solutions are required in addition to those already listed: $3 \%(\mathrm{v} / \mathrm{v})$ acetic acid; 0.1 and $2.0 \mathrm{~N}$ $\mathrm{HCl}$; Lloyd's reagent (Eli Lilly and Co.); $0 \cdot 2 \mathrm{~N}-\mathrm{NaOH}$.

A suitable sample of urine $(2 \mathrm{~min}$. excretion in the case of normal urines, less if the rate of excretion exceeded $50 \mathrm{mg}$./ $24 \mathrm{hr}$.) was measured into each of two graduated centrifuge tubes ( 1 and 2 ) and to tube 2 a known amount of $N$-methyl-2pyridone-5-carbonamide was added (usually $25 \mu \mathrm{g}$.); $0.5 \mathrm{ml}$. $3 \%$ acetic acid was then added to each tube and sufficient water to bring the total volume to $10 \mathrm{ml}$. $2 \mathrm{~N}-\mathrm{HCl}(0.5 \mathrm{ml}$.) and $0 \cdot 2 \mathrm{~g}$. Lloyd's reagent were added to each tube and the tubes were stoppered, shaken for $10 \mathrm{~min}$., and centrifuged. The supernatant fluid was poured off and the tubes were inverted to drain. The Lloyd's reagent in the tubes was washed by adding $5 \mathrm{ml}$. of $0 \cdot 1 \mathrm{~N}-\mathrm{HCl}$ to each tube, mixing the contents, centrifuging and pouring off the supernatant liquid. The tubes were then drained for $10 \mathrm{~min}$. Any fluid remaining at the necks of the tubes was wiped off, and $4 \mathrm{ml}$. $0 \cdot 2 \mathrm{~N}-\mathrm{NaOH}$ were added. The tubes were stoppered, shaken for $10 \mathrm{~min}$., and centrifuged. After it had been checked that the total volume was exactly the same in the two tubes (usually $4.5 \mathrm{ml}$.), $3 \mathrm{ml}$. of the supernatant fluid were in each case transferred to another centrifuge tube containing $2 \mathrm{ml}$. $\mathrm{M}-\mathrm{Pb}\left(\mathrm{NO}_{3}\right)_{2}$ solution. The $\mathrm{pH}$ was brought to $9 \cdot 2$ with $2.5 \mathrm{~N}-\mathrm{NaOH}$ (about $1.2 \mathrm{ml}$.), the volume made to $10 \mathrm{ml}$. with water, and the solution centrifuged and filtered as described in the previous section. Two $3 \mathrm{ml}$. samples of the filtrate from tube 1 were taken for analysis (test and test blank) and two $3 \mathrm{ml}$. samples from tube 2 (recovery and recovery blank); $1 \mathrm{ml}$. water was added to each tube. The procedure for colour development, measurement, and calculation of results was the same as that described in the previous section.

\section{Determination of N-methylnicotinamide in urine}

Decalso (Permutit Co. Ltd.) was activated by the method of Hochberg et al. (1945); 0.067 м phosphate buffer (pH 7) was prepared by mixing $40 \mathrm{ml} . \mathrm{KH}_{2} \mathrm{PO}_{4}$ solution (9.078 g./1.) and $60 \mathrm{ml} . \mathrm{Na}_{2} \mathrm{HPO}_{4}$ solution $\left(9 \cdot 465 \mathrm{~g}\right.$. anhydrous $\mathrm{Na}_{2} \mathrm{HPO}_{4} /$ 1.); $25 \%(\mathrm{w} / \mathrm{v}) \mathrm{KCl}$ solution.

Twenty-four hr. specimens of urine were collected under toluene, and, if not analysed at once, were preserved with glacial acetic acid $(10 \mathrm{ml} . / 24 \mathrm{hr}$. excretion) and stored in a refrigerator. A suitable sample of urine $(4 \mathrm{~min}$. excretion in the case of normal urines, less if the rate of excretion exceeded $20 \mathrm{mg}$. $N$-methylnicotinamide chloride $/ 24 \mathrm{hr}$.) was measured into each of two test tubes ( 1 and 2$)$. To tube 2 a known amount of $N$-methylnicotinamide chloride was added (usually 50 or $100 \mu \mathrm{g}$.). To both tubes $15 \mathrm{ml}$. buffer solution ( $\mathrm{pH} \mathrm{7)}$ were added and sufficient water to bring the volume to $30 \mathrm{ml}$. The solution was in each case poured on to an adsorption column (see Hochberg et al. 1945) containing 2 g. activated Decalso. The column was washed with three successive $5 \mathrm{ml}$. lots of water, sucking dry after each washing. The $N$-methylnicotinamide adsorbed on each column was eluted with hot $25 \%(\mathrm{w} / \mathrm{v}) \mathrm{KCl}$ solution and exactly $10 \mathrm{ml}$. of the eluate were collected in each case. Two $2 \mathrm{ml}$. samples of the eluate from column 1 (test and test blank) and two $2 \mathrm{ml}$. samples of the eluate from column 2 (recovery and recovery blank), were taken for colour development. Further $2 \mathrm{ml}$. samples of each eluate were measured out and titrated with $0 \cdot 2 \mathrm{~N}-\mathrm{NaOH}$ to the phenolphthalein end point to determine the amount of alkali required for neutralization. The appropriate amount of $0 \cdot 2 \mathrm{~N}-\mathrm{NaOH}(0 \cdot 05-0 \cdot 1 \mathrm{ml}$.) was added to each sample taken for analysis, before making the total volume to $4 \mathrm{ml}$. with water. The procedure for colour development, measurement and calculation of results was the same as that described in previous sections, except that hypobromite $(b)$ was used and spectrophotometer readings were taken at $500 \mathrm{~m} \mu$. after $1 \mathrm{hr}$. The factor $0 \cdot 794$ was used to convert the result into $N$-methylnicotinamide ion, and the factor 0.713 to express it in terms of nicotinic acid.

\section{Identification of metabolites on filter-paper chromatograms}

Filter-paper chromatography has been successfully used for the separation of a number of nicotinic acid metabolites in urine (see Reddi \& Kodicek, 1953), but up till the present time no suitable colour reaction has been available for the 
detection of $N$-methyl-2-pyridone-5-carbonamide on paper chromatograms. The possibility of using the present reaction for this purpose was therefore investigated. Preliminary experiments showed that azo colours could be produced on filter paper from all the nicotinic acid metabolites capable of giving the reaction in solution. The addition of phenol was not required, the filter paper itself apparently acting as an agent for the removal of excess of bromine. The diazotization and coupling technique could be simplified, without affecting the results, by applying a mixture of $\mathrm{HCl}$ and $\mathrm{NaNO}_{2}$, followed by a mixture of ammonium sulphamate and coupling agent. By the use of an $80 \%(v / v)$ aqueous solution of propanol as chromatographic solvent, it was possible to separate and identify each of the component substances in mixtures containing $N$. methyl-2-pyridone-5-carbonamide, $N$-methylnicotinamide and nicotinamide. The pyridone could also be readily identified in urine, but attempts to demonstrate the presence of $N$-methylnicotinamide and nicotinamide were unsuccessful.

Samples of urine were concentrated tenfold by evaporation in vacuo, and four successive $0.01 \mathrm{ml}$. portions applied to a sheet of Whatman no. 1 filter paper, the paper being dried thoroughly after each application (see Reddi \& Kodicek, 1953). In the case of other solutions a single $0.01 \mathrm{ml}$. portion was applied. After development of the chromatogram with $80 \%$ propanol the paper was left to dry. When all traces of the solvent had disappeared, light was excluded and the paper was sprayed with hypobromite solution (a) (see p. 515), left for $15 \mathrm{~min}$., and heated for $5 \mathrm{~min}$. in a hot air oven at about $100^{\circ}$. It was then sprayed, first with a mixture of equal parts of $2.4 \mathrm{~N}-\mathrm{HCl}$ and $0.1 \% \mathrm{NaNO}_{2}$, and $1 \mathrm{~min}$. later with a mixture of equal parts of $0.5 \%$ ammonium sulphamate and $0.1 \% N$-(l-naphthyl)-ethylenediamine dihydrochloride solution. The mixtures for spraying were prepared immediately before use and the paper sprayed lightly to minimize spreading of the spots.

Under the conditions described above, $R_{\boldsymbol{F}}$ values of $0 \cdot 24$ for $N$-methylnicotinamide, $\mathbf{0 . 6 0}$ for $N$-methyl-2-pyridone5-carbonamide, and $\mathbf{0 . 7 2}$ for nicotinamide were observed. As little as $1 \mu \mathrm{g}$. of $N$-methyl-2-pyridone-5-carbonamide or $2 \mu$ g. of nicotinamide or $N$-methylnicotinamide, could be detected.

\section{RESULTS AND DISCUSSION}

\section{Accuracy of the methods}

The relationship between the extinction ( $E$ value) of the colour formed and the amount of the test substance taken for colour development was very nearly linear in all cases. Typical calibration curves for the two pyridones and for $N$-methylnicotinamide and nicotinamide are shown in Fig. 2. The precision of the method for colour development was tested by developing and reading a series of twelve tubes each containing $25 \mu \mathrm{g}$. of $N$-methyl-2-pyridone-5-carbonamide, and a similar number containing $25 \mu \mathrm{g}$. of $N$-methylnicotinamide. The standard deviation of $E$ values from the mean was $\pm 1.1 \%$ for the pyridone and $\pm 0.5 \%$ for $N$ methylnicotinamide.

Although urea reacts with hypobromite, the presence of amounts up to $4 \mathrm{mg}$. had no appreciable

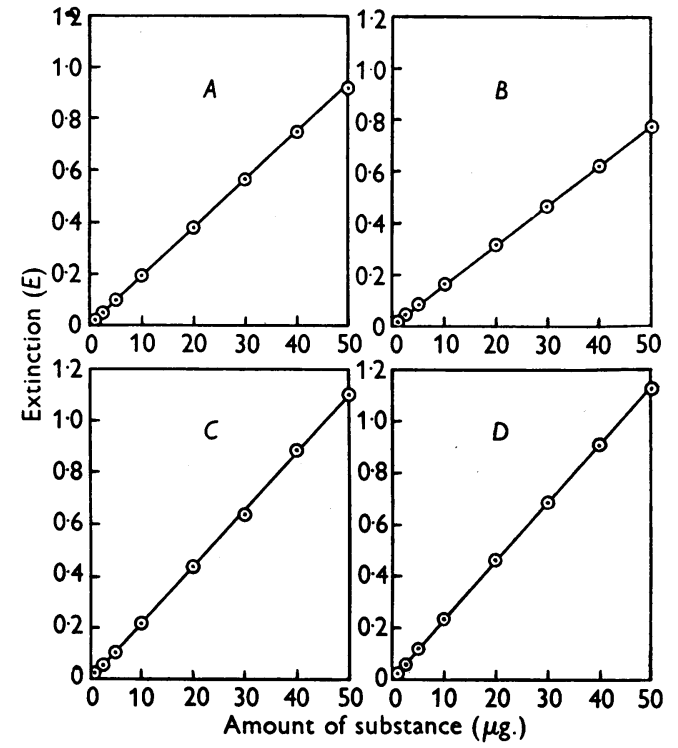

Fig. 2. Relationship between amount of substance taken for analysis and the extinction $(E)$ of the colour produced. Readings taken in a Beckman spectrophotometer using $1 \mathrm{~cm}$. cells. $A, N$-methyl-2-pyridone-5-carbonamide read at $590 \mathrm{~m} \mu . ; B, N$-methylnicotinamide chloride at $500 \mathrm{~m} \mu$.; $C, \quad N$-methyl-2-pyridone-3-carbonamide at $590 \mathrm{~m} \mu . ; D$, nicotinamide at $500 \mathrm{~m} \mu$.

effect on colour formation by $N$-methyl-2-pyridone5-carbonamide. Alcohols (e.g. ethanol and propanol) interfered with the diazotization process, giving an evanescent red colour. Azo colours were produced by various primary aromatic amines, but could be distinguished from the colours due to acid amides, since hypobromite treatment was not required for their formation.

In applying the methods to urine it was necessary to correct, by means of internal standards, for interference from other urinary constituents or for incomplete recovery from adsorbents. This procedure prevented a systematic error, but reduced the reproducibility of individual results. In the case of the method for $N$-methyl-2-pyridone-5-carbonamide, the variation between duplicates amounted to $1-5 \%$. The method for $N$-methylnicotinamide was less precise, due principally to variability in the recovery from the adsorption process, but also to the relatively high blank. Since the average variation between duplicates was $14 \%$, it was essential for all determinations of this metabolite to be made in duplicate and the mean taken.

\section{Comparison with other methods}

The present method for $N$-methyl-2-pyridone-5carbonamide is superior both in speed and accuracy to the method of Holman \& Lous (1951). The 
method for $N$-methylnicotinamide has the advantages that it does not require the use of fluorimetric apparatus, and that it can be used in conjunction with the method for the pyridone with little alteration in reagents, technique or equipment. A series of urine samples was analysed by the present methods, and also by the fluorimetric method of Carpenter \& Kodicek (1950) for $N$ methylnicotinamide, and by the nitration method of Holman \& Lous (1951) for $N$-methyl-2-pyridone-5carbonamide. The results (Table 4) show satisfactory agreement between methods, but there was a tendency in the case of the pyridone for values to be slightly lower by the azo than by the nitration method.

\section{Application of the methods}

The present methods were used to investigate the comparative effects of dosing with nicotinic and quinolinic acids on the excretion of nicotinic acid metabolites by man. Henderson (1949) showed that the administration of large amounts of quinolinic acid to rats caused an increase in the excretions of nicotinic acid and $N$-methylnicotinamide. Krehl, Bonner \& Yanofsky (1950) and Reddi \& Kodicek
(1953) confirmed these results for the rat, but did not extend their observations to man. They concluded that the conversion of quinolinic acid into nicotinic acid and its metabolites by the rat probably represents a side reaction rather than a main pathway in nicotinic acid metabolism.

The urinary excretions of $N$-methyl-2-pyridone5-carbonamide and $N$-methylnicotinamide by an adult subject (W.I.M.H., aged 38 years) receiving a normal diet were determined before and after oral and intravenous administration of $300 \mathrm{mg}$. of quinolinic acid, and before and after oral administration of an equivalent amount of nicotinic acid (221 mg.). In the case of two further subjects (A.B.M., aged 30, and E.M.W., aged 42 years) the excretion of each metabolite was determined before and after oral administration of $600 \mathrm{mg}$. of quinolinic acid. Nicotinamide and nicotinic, and nicotinuric, acids could not be determined by the present methods, but it has been shown that, although they may be excreted after dosing with nicotinic acid (Reddi \& Kodicek, 1953), the total amounts excreted do not represent a very large proportion of the dose administered, the combined excretions of acid-hydrolysable derivatives (nico-

Table 4. Comparison between results obtained by different methods of analysis

\begin{tabular}{|c|c|c|}
\hline \multirow[b]{2}{*}{$\begin{array}{c}\text { Urine } \\
\text { specimen }\end{array}$} & \multicolumn{2}{|c|}{$\begin{array}{l}N \text {-Methylnicotinamide ion } \\
\text { exeretion }(\mathrm{mg} . / 24 \mathrm{hr} \text {.) } \\
\text { found by }\end{array}$} \\
\hline & $\begin{array}{c}\text { Proposed } \\
\text { method }\end{array}$ & $\begin{array}{c}\text { Method of } \\
\text { Carpenter \& } \\
\text { Kodicek (1950) }\end{array}$ \\
\hline $\begin{array}{l}\mathbf{1} \\
\mathbf{2} \\
\mathbf{3} \\
\mathbf{4} \\
\mathbf{5}\end{array}$ & $\begin{array}{c}6 \cdot 0 \\
30.9 \\
\overline{9.5} \\
4 \cdot 4\end{array}$ & $\begin{array}{r}5.9 \\
31 \cdot 7 \\
\overline{10 \cdot 0} \\
4.8\end{array}$ \\
\hline
\end{tabular}

\begin{tabular}{|c|c|}
\hline $\begin{array}{c}\text { Proposed } \\
\text { method }\end{array}$ & $\begin{array}{c}\text { Method of } \\
\text { Holman \& Lous } \\
(1951)\end{array}$ \\
\hline $\begin{array}{c}13 \cdot 6 \\
101 \\
14 \cdot 4 \\
13 \cdot 8 \\
16 \cdot 9\end{array}$ & $\begin{array}{c}14 \cdot 6 \\
101 \\
15 \cdot 6 \\
14 \cdot 3 \\
18 \cdot 0\end{array}$ \\
\hline
\end{tabular}

Table 5. Comparative effects of administration of quinolinic and nicotinic acids on the urinary excretions of N-methylnicotinamide and N-methyl-2-pyridone-5-carbonamide by humans

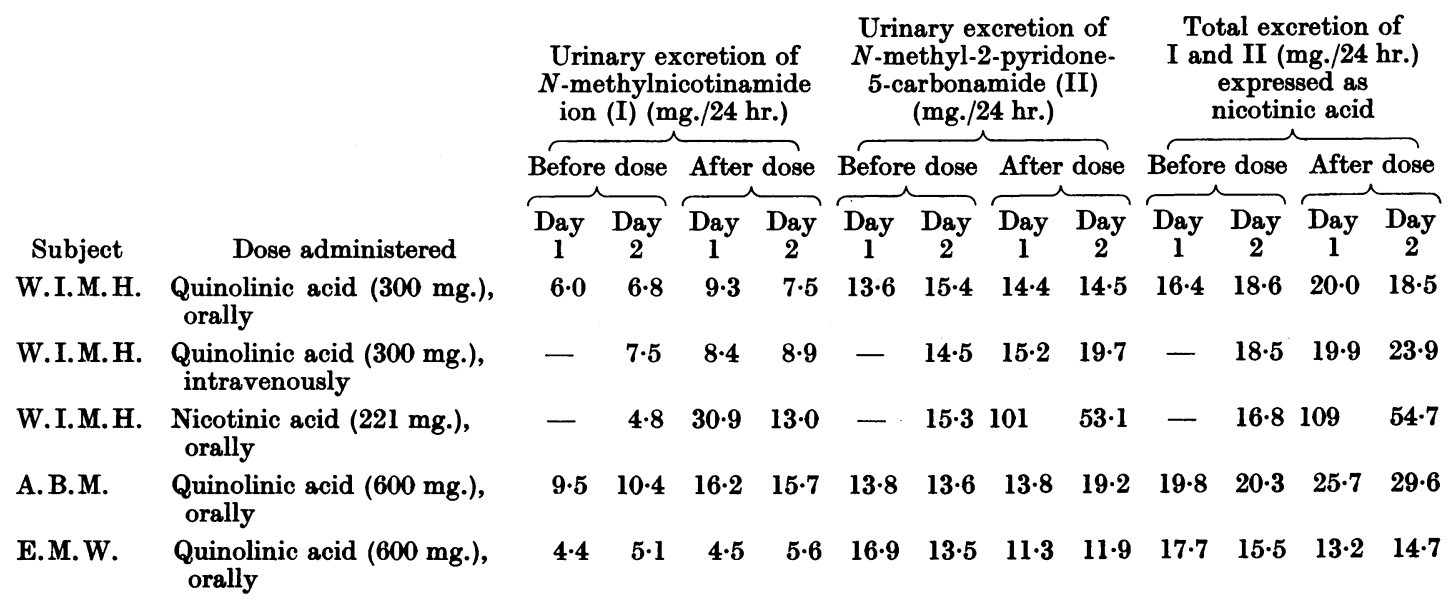


tinic acid, nicotinuric acid and nicotinamide) in the first $72 \mathrm{hr}$. after ingestion of $500 \mathrm{mg}$. nicotinic acid being only $16-30 \%$ of the dose (Holman \& Lange, 1950). The quinolinic acid used was supplied by Messrs L. Light and Co. It was further purified via the dimethyl ester and finally recrystallized twice from hot water. The experimental results are shown in Table 5.

It is clear that the administration, either orally or intravenously, of a comparatively large dose of quinolinic acid had very little effect on the excretions of $N$-methylnicotinamide and pyridone. The results for subjects W.I.M.H. and A.B.M. show some indication of a slight increase in the levels of excretion, but the effect is insignificant in comparison with that observed after administration of nicotinic acid. In the case of subject W.I.M.H., nicotinic acid was 37 times as effective as quinolinic acid in raising the total excretion of $N$-methylnicotinamide and pyridone.

The results support the conclusion that in man, as well as in the rat, quinolinic acid is probably not an important intermediate in nicotinic acid metabolism.

\section{SUMMARY}

1. Since the main metabolites of nicotinic acid normally excreted in human urine are acid amides, the possibility was investigated of developing a colorimetric method for their determination in urine, based on conversion of the carbonamide into an amino group by heating with hypobromite, followed by diazotization and coupling of the amino compound formed to yield an azo dye.

2. It was found that when the excess of hypobromite was suitably controlled, and $N$-(1-naphthyl)-ethylenediamine dihydrochloride was used as coupling agent, azo colours could be produced from $N$-methyl-2-pyridone-5-carbonamide, $N$-methyl2-pyridone-3-carbonamide, $N$-methylnicotinamide and nicotinamide.
3. Optimum conditions for colour production were ascertained and a method worked out for the determination of amounts of from 1 to $50 \mu \mathrm{g}$. of each of the colour-producing substances.

4. The removal from urine of substances which interfere with the colour reaction was investigated, and procedures are described which were found suitable for the determination of $N$-methyl-2pyridone-5-carbonamide and $N$-methylnicotinamide in human urine.

5. Using the present methods, the urinary excreations of nicotinic acid metabolites by three adult subjects were determined before and after administration of quinolinic acid. The results showed evidence of no more than a slight conversion of quinolinic into nicotinic acid.

The author wishes to thank Prof. R. A. McCance, C.B.E., F.R.S., and Dr E. M. Widdowson for their interest and valuable criticism, and Dr E. Kodicek for the gift of a sample of coenzyme $I$.

\section{REFERENCES}

Bratton, A. C. \& Marshall, E. K. jun. (1939). J. biol. Chem. 128, 537.

Carpenter, K. J. \& Kodicek, E. (1950). Biochem. J. 46, 421. Goodyear, J. M. \& Murphy, H. W. (1944). J. Amer. pharm. As8. 33, 129.

Henderson, L. M. (1949). J. biol. Chem. 181, 677.

Hochberg, M., Melnick, D. \& Oser, B. L. (1945). J. biol. Chem. 158, 265.

Holman, W. I. M. \& Lange, D. J. de (1949). Biochem. J. 45, 559.

Holman, W. I. M. \& Lange, D. J. de (1950). Nature, Lond., $165,604$.

Holman, W. I. M. \& Lous, P. (1951). J. Physiol. 114, 255.

Krehl, W. A., Bonner, D.\& Yanofsky, C. (1950). J. Nutr.41, 159.

Reddi, K. K. \& Kodicek, E. (1953). Biochem. J. 53, 286.

Sidgwick, N. V., Taylor, T. W. J. \& Baker, W. (1937). The Organic Chemistry of Nitrogen, new ed. Oxford: Clarendon Press.

Smith, H. W., Finkelstein, N., Aliminosa, L., Crawford, B. \& Graber, M. (1945). J. clin. Invest. 24, 388. 